\title{
Simple Preparations and Characterizations of Activated-Carbon- Clothes from Palm-Kernel-Shell for Ammonia Vapor Adsorption and Skim-Latex-Odor Removal
}

\author{
Muhammad Adlim ${ }^{1,2}$, Ratu Fazlia Inda Rahmayani², Fitri Zarlaida ${ }^{2}$, Latifah Hanum² ${ }^{2}$ Maily Rizki², \\ Nurul Ummi Manatillah ${ }^{2}$, and Omar Muktaridha ${ }^{1}$ \\ ${ }^{1}$ Graduate School of Mathematics and Applied Science, Universitas Syiah Kuala, Banda Aceh 23111, Indonesia \\ ${ }^{2}$ Chemistry Department, FKIP Universitas Syiah Kuala, Darussalam, Banda Aceh 23111, Indonesia
}

\author{
* Corresponding author: \\ tel: $+62-651-7553205$ \\ email:adlim@unsyiah.ac.id \\ Received: January 25, 2021 \\ Accepted: April 4, 2021
}

DOI: $10.22146 /$ ijc. 63570

\begin{abstract}
This study explored a simple preparation and characterization of the activated carbon and cloth from the palm kernel shell and compared it to the commercialwater-filter-carbon specification. A new pyrolysis chamber that is easily scaled up using the palm kernel shell itself as a heat source was tested. Two different steps were compared: the alkaline activation process performed before or after the carbonation process in the palm-kernel-shell carbon preparation. The palm-kernel-shell activated carbons prepared with the current method fulfilled the standard quality of activated charcoal except for the ash content. The sequencing step of the preparation affected the adsorption capacity. Instead of the reverse sequence, the soaking palm kernel shells in $\mathrm{NaOH}$ before the carbonation process lead to a higher adsorption capacity. The carbon particle stability on the cloth surface was affected by both the adhesive concentration and its size. The ammonia adsorption capacity of activated carbon cloth (ACC) was between 1-4 mg ammonia per $g$ stuck carbon. The preparation and the carbon type source on ACC affected the adsorption capacity. The ACC absorbed and lessened the skim latex odor vapor, nearly odorless depending on the ACC area and the volume of odor vapor.
\end{abstract}

Keywords: agriculture; adsorption capacity; activation; carbonation

\section{- INTRODUCTION}

The odor from ammonia is one of the major problems experienced in daily life. It has been discovered to be originating from trash bins and, on a large scale, agricultural industry and municipal organic wastes. The primary source of ammonia emission is cattle farming, as observed with its $49 \%$ contribution ( $244 \mathrm{kT}-\mathrm{NH}_{3}$ ) in the United Kingdom in 2016. Other sources include livestock, agriculture, human and vehicle wastes, etc. [1]. However, it is possible to detect the odor in the concentration range of 5-53 ppm and has also been observed to have the ability to spread to other rooms at $50 \mathrm{ppm}$ in $10 \mathrm{~min}$. The poison effect of ammonia depends on its emission concentration level in the air. Inhaling vapor at 570 ppm causes respiratory interferences and sore feelings in the tract [2].

Several other things are causing severe air pollution in Asian countries, including Indonesia. These include lousy odor from rubber processing industries as observed in 2016 by merdeka.com and detik.com to disturb Mojokerto. Other similar cases have also been reported in different places since the country produces $>$ 3 million tons of rubber in 2016, with more than a $1.3 \%$ increase in production annually. The air pollution was associated with the focus of these factories on treating liquid wastes [3] even though every step of treating skim latex also produces an unpleasant odor. A new smoke chamber prototype for rubber latex sheets was published previously [4-5], but there is no mention of reducing the smell, especially during the drying process.

One of the solutions to reduce ammonia and skim latex odor is the use of an adsorbent-based treatment. However, despite the reputation of granular activated carbon as an absorbent [6] and odor removal mainly for water and gas, it is barely used to remove the odors in the skim latex vapor [7-10]. The process involves filling

Muhammad Adlim et al. 
a container with the granular or powder content to make the carbon particles denser and reduce their absorbing capacity. Carbon cloth is suggested to be more compatible than the granular ones but expensive due to its source as well as the carbonization and activation processes [11-12]. This material has several applications, including its use as a chemical protecting blanket or jacket [13]. Anti-odor textile fabricated from palm kernel shells has been reported for onion odor adsorption [14]. However, the carbon cloth prepared with a simpler method has been reported for ammonia vapor adsorption.

In the current study, the activated carbon was prepared from the waste of palm kernel shells using a simple method, which is easy for farmers in rural areas to apply. It is important to note that this specific product has not been comprehensively explored by past studies [15]. For a simple process, palm kernel was used as the fuel for carbonization in two-layer-cylindrical-pyrolysis chambers. At the same time, caustic soda was applied as the activating agent due to its availability in the rural market.

The current study explores the effect of the activation-carbonation sequence, which is crucial to prevent the corrosive chemical loaded into the pyrolysis chamber. The characteristics of the activated carbons were compared with the new and the regenerated commercial activated carbons. The immobilization methods of activated carbon on a fabric, the capacity for ammonia odor adsorption, and skim latex odor removal were unknown. These areas have not been much discussed in previous literature because most of them are focused on the immobilization of active matter on activated carbon [16]. Therefore, the stability of activated carbon cloths, adsorption capacity, and organoleptic studies on odor removal were explored.

\section{- EXPERIMENTAL SECTION}

\section{Materials}

Several research materials were bought from several companies. Palm Kernel Shells were from palm plantation (PT. Perkebunan Lembah Sakti). Ethanol (ACS grade), ammonia (25\%), hydrochloric acid (35\%), Nessler reagent $\mathrm{A}$, and methylene blue were all from Supelco Merck. Commercial caustic soda (flake 98\%), water filter commercial activated carbon (Hexagon coconut shells ${ }^{\circledR}$ ) and polyvinyl acetate glue were from a local market.

\section{Instrumentation}

Some analytical instruments were used for characterization. An analytical instrument of UV-Vis Spekol 2000 spectrophotometer was used for the determination of ammonia concentration. A trinocular Olympus CX41 microscope with camera DP12, a Bellstone stereo microscope with an optical camera was used to observe the ACC surfaces. Brunauer-EmmettTeller (BET) Sorptomatic 1800 is used to analyze carbon porosity, and scanning electron microscopy (SEM) JEOL JSM-6510LA was for surface characterization of activated carbons.

\section{Procedure}

\section{Preparation of activated carbon from palm kernel shell}

Dried palm kernel shells (PKS) were obtained from the local (Aceh Selatan) palm oil industry. About $16 \mathrm{~kg}$ was washed, sun-dried, and divided into two containers. It was divided into two groups of treatments. In the first treatment, PKS was initially carbonized by pyrolysis methods before alkaline activation. Alkaline activation is done by soaking it into $25 \% \mathrm{NaOH}$ for $24 \mathrm{~h}$. The charcoal was filtered and washed with deionized water until neutral and then sun-dried. This variation was called "Palm-carb-prior-act-C". The second treatment involved the initial soaking of the PKS into $25 \% \mathrm{NaOH}$ for $24 \mathrm{~h}$ and sun-dried before it was carbonized within a pyrolysis chamber. The cold charcoals were washed until they have a neutral $\mathrm{pH}$ and sun-dried, and the variation was called "Palm-act-prior-carb-C".

Carbonization was conducted in a pyrolysis chamber; other than PKS filled in a pyrolysis chamber, the heat source was the burning PKS itself. The combustion equipment is made of two different sizes of hollow metal cylinders. The inner (smaller size), the pyrolysis tube, was shielded from the air, and the outer was the combusting chamber, where PKS was continuously added as fuel to produce the heat for pyrolysis. The combustion was adiabatic took $3 \mathrm{~h}$, and the temperature reached around $800-1000{ }^{\circ} \mathrm{C}$, which 
was controlled by continuous addition of PKS as the fuel to simulate the actual application in the community. For comparison, both a new commercial-water-filter-carbon (WF-C) and the regenerated ones (RWF-C) were also studies. Each material was included in the characterization and fabrication of the Activated Carbon Cloths (ACC). The new and used WF-C were obtained from the local refill-water depot under a similar trade name, hexagon coconut shell (granular, ASTM American Society for Testing Materials quality). For RWF-C sample preparation, the WF-C that was previously used for three years was regenerated by drying at $105^{\circ} \mathrm{C}$ for $2 \mathrm{~h}$, reactivated by soaking in $6 \mathrm{M} \mathrm{HCl}$ for $24 \mathrm{~h}$, and then washed and neutralized [17].

\section{Characterization of the activated carbon}

All types of activated carbon were characterized in powder with a size of more than 100 mesh. Characterization of the activated carbon was conducted for moisture, ash, iodine number, and volatile compound. The surface area and morphology were analyzed respectively using Brunauer-Emmett-Teller (BET) Sorptomatic 1800 and scanning electron microscopy (SEM) JEOL JSM-6510LA. The characteristic of activated carbon level for each referred to ASTM D-3175-11, ASTM D-3175-02, ASTM D-3174-11, and ASTM D-4607-94 respectively.

\section{Immobilization/supported technique of activated carbon on the cloth}

Each type of activated carbon particles $(0.3 \mathrm{~g})$ was immobilized on the surface of cotton cloth $(4 \mathrm{~cm} \times 7 \mathrm{~cm})$ by using polyvinyl acetate adhesive (PAA), which was prepared in various concentrations of $50,60,70$, and 80 $\%$-weights-volume in technical-grade ethanol. The adhesive was smeared and flattened on the surface of the cotton cloth by using a roller grinder before the activated carbon particles flattened by a 5 -kg-roller-grinder. The experiments were repeated to search for a combination between the adhesive concentration and the particle size of activated carbon $(60,80$, and 100 mesh prepared with several layer sieves), which is crucial for the particle stickiness on the cloth. The best combination was determined from the stability of the carbon stickiness measured as the percentage of the mass loss in the immobilized carbon cloth after it was spun in a rotary evaporator for $5 \mathrm{~min}$ at $40 \mathrm{rpm}$. The stability test was run to study the ACC endurance in packaging and friction. The particle dispersion homogeneity was compared based on the microscope images.

\section{Ammonia adsorption test}

Approximately $25 \%$ of concentrated ammonia (Merck, 105432 Supelco) was transferred in a small baker glass, cooled in an ice bath $\left(\sim 15^{\circ} \mathrm{C}\right)$ for $10 \mathrm{~min}$ to avoid excessive evaporation. Later, $0.1 \mathrm{~mL}$ of chilly ammonia was transferred using a micropipette into several 250$\mathrm{mL}$-glass reactors (equipped with electric plastic film cover) in which carbon cloth sheets were hung, as shown in Fig. 1. All glass reactors were airtight-shield and placed in a water batch at $28 \pm 1{ }^{\circ} \mathrm{C}$. The initial $\mathrm{pH}$ of ammonia vapor within the closed container was neutral, the $\mathrm{pH}$ was not controlled, but there was no significant change during this gas-phase experiment. This also confirmed with the theory that in the gas phase, ammonia does not significantly change $\mathrm{pH}$ [18]. The ACC sheets have a dimension(@3.5 cm $\times 6.5 \mathrm{~cm}$, containing each $0.25 \mathrm{~g}$ average weight of activated carbon). The ACCs were attached inside the surface of the glass reactors except for the control. Adsorption experiments were set up in various ACC sheets $(0,1,2,3,4$, and 5 sheets). The optimum contact time was determined at the time when the amount of absorbed ammonia reached a constant. For this experiment, four sheets of ACC were hung in the glass reactor. Then, $0.1 \mathrm{~mL}$ of cold $25 \%$ concentrated ammonia was transferred into each six glass reactors using a micropipette. The initial concentration of ammonia vapor, which was $0.1 \mathrm{~mL}$ $(13.38 \mathrm{M})$ within $250 \mathrm{~mL}$ container at $28^{\circ} \mathrm{C}$ was $0.0052 \mathrm{M}$. The reactors were kept in a water bath at $28{ }^{\circ} \mathrm{C}$ and shielded with silicone rubber sheets to maintain an airtight condition with each was labeled according to the experimental-time, including $0,60,90,105,120,135$, and $150 \mathrm{~min}$. At the due time, the carbon cloth sheets were quickly transferred into a $250 \mathrm{~mL}$ Erlenmeyer, which was covered with a rubber stopper connected to a $50 \mathrm{~mL}$ burette containing distilled water to ensure they absorbed the ammonia dissolved into the distilled water. After 10 min of agitation, the filtrate was analyzed using 
a UV-Vis Spekol 2000 spectrophotometer with Nessler reagent as the complexing agent for the ammonium. The standard solution used, $\mathrm{NH}_{4} \mathrm{Cl}$, was verified using the previous method [19], which involved determining the ammonia concentration before and after adsorption. The adsorption capacity of the adsorbent in equilibrium isothermal Langmuir adsorption was calculated using Eq. (1) and (2), which is known as the Hannes-Woolf model, as follows [20-21]:

$\frac{\mathrm{C}_{\mathrm{e}}}{\mathrm{q}_{\mathrm{e}}}=\frac{1}{\mathrm{q}_{\mathrm{m}} \mathrm{K}_{\mathrm{l}}}+\frac{\mathrm{C}_{\mathrm{e}}}{\mathrm{q}_{\mathrm{m}}}$

or modified into

$\frac{\mathrm{C}_{\mathrm{e}}}{\mathrm{q}_{\mathrm{e}}}=\frac{1}{\mathrm{bK}}+\frac{\mathrm{C}_{\mathrm{e}}}{\mathrm{b}}$

where $C_{e}$ is the concentration of ammonia vapor at equilibrium ( $\mathrm{mg} \mathrm{g}^{-1}$ ), $\mathrm{K}_{1}$ is Langmuir constant related to adsorption capacity $\left(\mathrm{mg} \mathrm{g}^{-1}\right), \mathrm{q}_{\mathrm{e}}$ is total ammonia vapor adsorbed per gram of immobilized carbon $\left(\mathrm{mg} \mathrm{g}^{-1}\right), \mathrm{b}=$ maximum adsorption capacity per gram of immobilized carbon ( $\left.\mathrm{mg} \mathrm{g}^{-1}\right), \mathrm{K}=$ equilibrium constant ( $\mathrm{L} / \mathrm{mg}$ ).

\section{Adsorption of volatile organic compounds (VOCs) from skim latex}

The coagulated skim latex was cut into small pieces to a dimension of $1 \mathrm{~cm} \times 1 \mathrm{~cm} \times 5 \mathrm{~cm}$, and the weight was estimated to be $10 \mathrm{~g}$. Every four pieces were kept in 16 of $100 \mathrm{~mL}$-rubber-sealed vials prepared for latex VOC sources for five days to concentrate the VOCs, as shown in Fig. 1(a). Three types of immobilized ACC named (a) Palm-carb-prior act-C, (b) Palm-act-prior carb-C and, (c) commercial water filtration (WF-C) were prepared from four types of carbon sources and hung inside a $250 \mathrm{~mL}$ Beaker glass as the reactor as indicated in Fig. 1(b). Meanwhile, the immobilized ACC sheets, each with a dimension of $3.5 \mathrm{~cm} \times 6.5 \mathrm{~cm}\left(22.75 \mathrm{~cm}^{2}\right)$, were varied at $0,2,3,4$, and 5 sheets per reactor and combined with having three replications. Each reactor was shielded with an elastic rubber sheet to ensure airtight, as shown in Fig. 1. Furthermore, $10 \mathrm{~mL}$ of VOC was transferred from a vial into the reactor using a syringe after adsorption time was initiated, and the experiments were conducted at 0,60 , 120 , and $135 \mathrm{~min}$.

\section{Organoleptic test odor}

Twenty undergraduate chemistry students, including

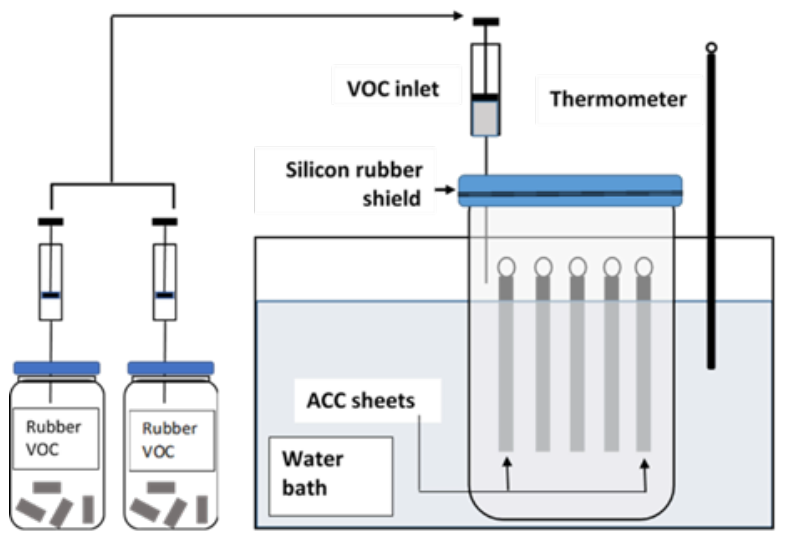

Fig 1. Vapor adsorption experiment. Skim latex VOC source (left) and vapor adsorption reactor equipped with ACC sheets (right)

ten males and ten females within the age range of 21-23 years volunteered to participate in the organoleptic test for skim latex (VOC) odor removal using the method used by a previous study [22]. They were made to smell four shield-caps containing different concentrations of VOCs at 10,5 , and $0 \mathrm{~mL}$ during calibration. The level of odor in organoleptic sheets was recorded using a $0-10$ level scale with the provision of a space to write an extreme level if they want to grade or respond differently. However, during the experiment, each of the participants separately smelled five caps containing a similar level of VOC but a different number of ACC sheets $(0,2,3,4$, and 5 sheets) and then recorded the odor level in the organoleptic-observation table.

\section{- RESULTS AND DISCUSSION}

\section{Preparation and Characterization of Activated Carbon from Palm Kernel Shells}

The sequence of activation-carbonization was compared, and the treatment initially carbonized before chemical activation (Palm-carb-prior-act-C) was found to have produced hard charcoals and less yield. Still, better characteristics were observed in the reverse treatment, which was initially activated before carbonization (Palm-act-prior-carb-C) as observed from 37.5 and $42.86 \%$ yields, respectively. These were, however, considered higher than the results of a previous study [23]. Furthermore, the activated carbon was discovered to have produced more micropore than other raw 
materials [24-26], as shown in the surface images obtained from SEM and compared with commercialgrade water filter carbons as presented in Fig. 2. The SEM images with similar 5000 times magnification in Fig. 2 show palm-carb-prior act-C (a) has smaller pores than Palm-act-prior carb-C (b). In comparison, the water filter carbon (c) was discovered to have more pores than those regenerated (d). Therefore, the products shown in Fig. 2(b) and Fig. 2(c) should have higher adsorption capacity.

The physical and chemical parameters fulfilled the minimum Indonesian National Standard (SNI). It is also comparable to ASTM minimum standards except for ash content, which was not preferable, as shown in Table 1. The characteristics correlate with the chemical properties of the activating agent. The chemical reaction produced some insoluble materials that cover the pores of carbon, and then it will subsequently reduce the adsorption capacity [27]. Therefore, more soluble activating chemicals are preferable, but there is a need to consider the toxicity level, cost, and availability in rural areas. Moreover, physical activation was also confirmed to be the better choice but requires a high-pressure reactor, which also has cost consequences.

The stability of the immobilized-activated-carbon on the cotton cloth was deduced from the weight loss percentage after ACC was rotated in a rotary evaporator at $40 \mathrm{rpm}$ for $5 \mathrm{~min}$. The results showed the most stable ACC was prepared with $80 \mathrm{wt} . \%$ of the adhesive and 100 mesh activated carbon particles. The smallest percentage of carbon particle loss was produced at this condition, leaving the highest percentage on the cloth. The data were confirmed using light microscope images present in
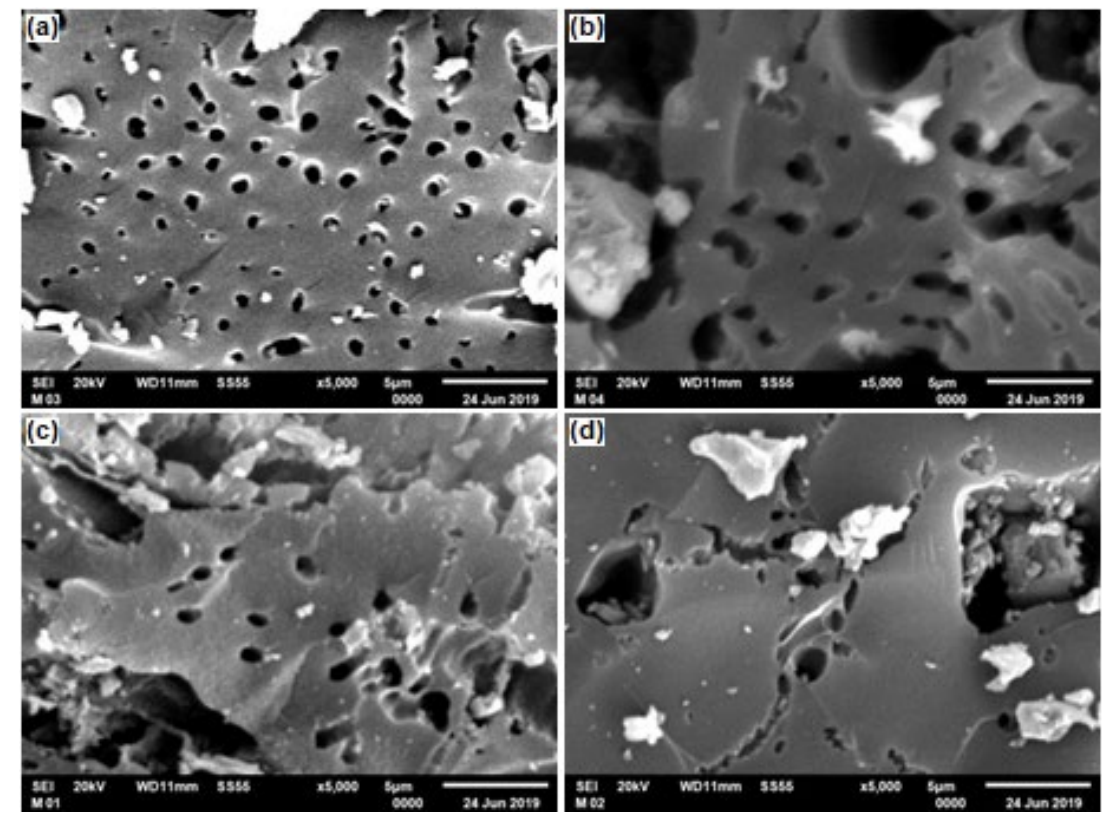

Fig 2. SEM images of the ACC (a) Palm-carb-prior act-C, (b) Palm-act-prior carb-C. (c) water filtration carbon (WFC), (d) regenerated filtration regeneration (RWF-C)

Table 1. Activated carbon quality standard based on Indonesian National Standard (SNI), and comparable to ASTM

\begin{tabular}{|c|c|c|c|c|c|}
\hline Parameters & Palm-carb-prior-act-C & Palm-act-prior-carb-C & RWF-C & WF-C & SNI \\
\hline Water content (\%) & 8.20 & 5.70 & 11.80 & 13.90 & $\leq 15$ \\
\hline Ash content (\%) & 8.20 & 13.80 & 12.70 & 11.50 & $\leq 10$ \\
\hline Volatile compound (\%) & 24.00 & 25.00 & 23.27 & 21.50 & $\leq 25$ \\
\hline Iodine number $\left(\mathrm{mg} \mathrm{g}^{-1}\right)$ & 920.24 & 1113.81 & 1132.85 & 1259.78 & $\geq 750$ \\
\hline Methylene Blue $\left(\mathrm{mg} \mathrm{g}^{-1}\right)$ & 178.18 & 203.59 & 419.73 & 433.18 & $\geq 120$ \\
\hline
\end{tabular}


Fig. 3 and 4, which showed the most dispersed and homogeneous carbon particles, were observed in ACC prepared with 80 wt.\% of the adhesive and 100 mesh carbon particles as indicated in Fig. 3 and Fig. 4. Fig. 3 shows that at a constant of $80 \%$ adhesive, the smaller carbon particle gave the more homogeneous carbon stickiness on the cloth. Fig. 3(c) is the dark color indicating the better carbon particle dispersion. Attempting to increase the ACC flexibility using lower adhesive concentration $(<80 \mathrm{wt} . \%)$ caused less carbon particle dispersion. As shown in Fig. 4 (a-c), carbon particles did not completely cover the cloth surface.

The results of the Brunauer-Emmett-Teller (BET) analysis for each type of activated carbon are presented in Fig. 5, and the adsorption-desorption plot was essential to elaborate the adsorption layered model, quantity of the pollutant adsorbed, pollutant holding ability, etc. All the curves were found to have exhibited good adsorption points at $1 \mathrm{~atm}$, with the curve pattern observed somewhat similar to type III isotherm with the hysteresis loop, as found in the literature [28].

Alkaline activation after carbonation (the palmcarb-prior act-C in Fig. 5(a)) showed a lower adsorption capacity $\left(50 \mathrm{~cm}^{3} \mathrm{~g}^{-1}\right)$ compared to revised step activation (palm-act-prior carb-C in Fig. 5(b)), which was up to $600 \mathrm{~cm}^{3} \mathrm{~g}^{-1}$. Fig. 5(a) demonstrated an adsorption capacity despite the fact the adsorbed quantity was relatively low. This desorption trend indicated the gas was strongly held at reduced pressure. The pore volume of the palm-act-prior carb-C was $1.012 \mathrm{~g} \mathrm{~cm}^{-3}$, higher than
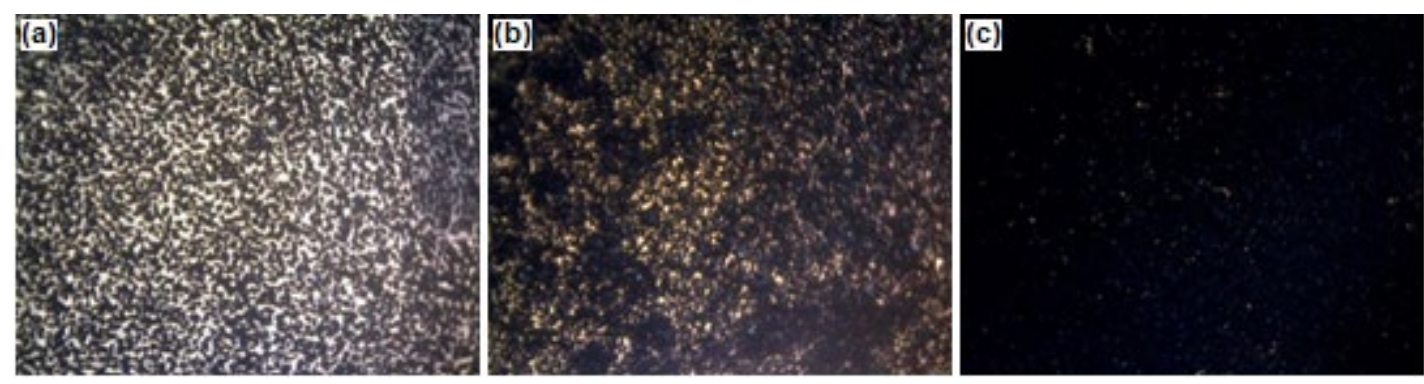

Fig 3. Light microscope images of ACC surfaces prepared with several carbon particle sizes using $80 \mathrm{wt} . \%$ adhesive: (a) 60, (b) 80, and (c) 100 mesh
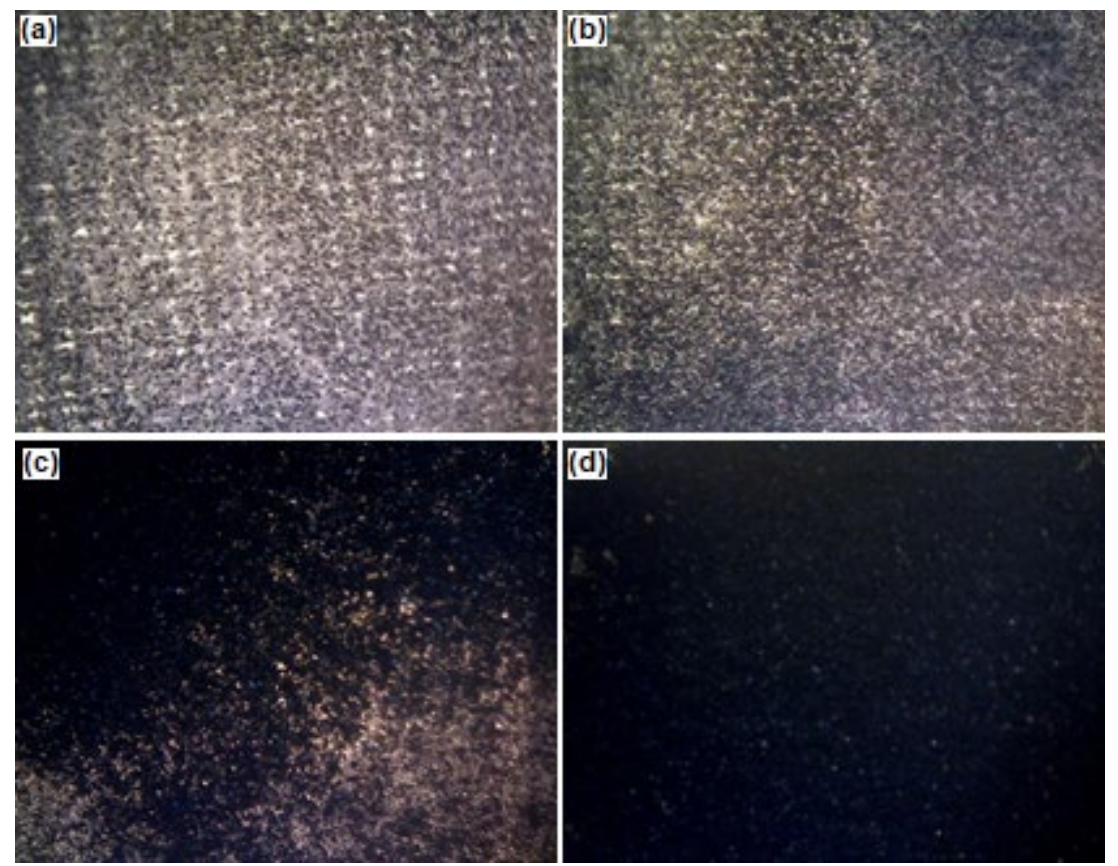

Fig 4. ACC surfaces prepared with various concentrations of adhesive: (a) 50, (b) 60, (c) 70, and (d) 80 wt.\% 

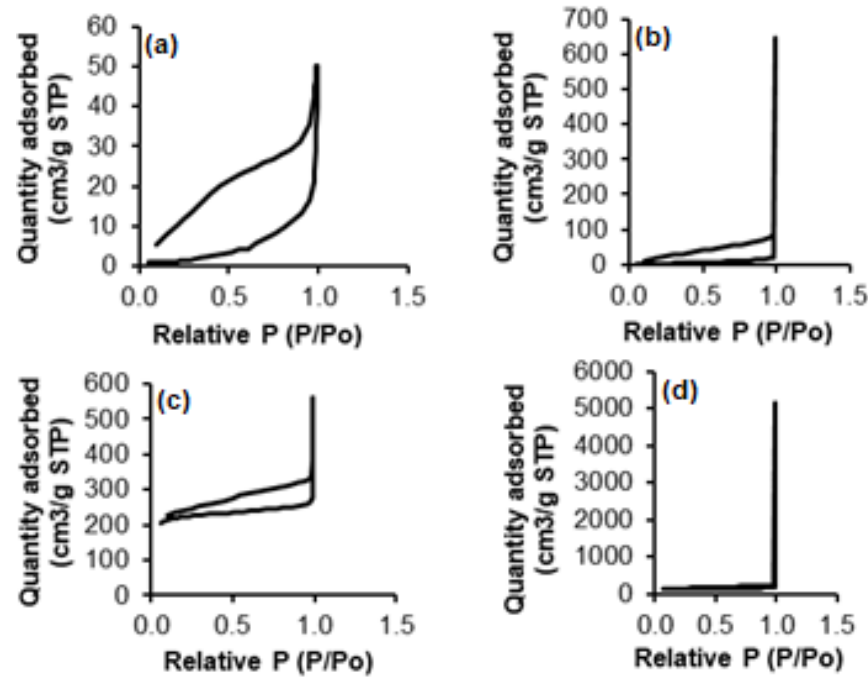

Fig 5. Adsorption-desorption isotherm plots of the activated carbons; (a) Palm-carb-prior act-C, (b) Palmact-prior carb-C, (c) water filter carbon (WF-C), (d) regenerated filter carbon (RWF-C) that of the water filter carbon (WF-C) of $0.56 \mathrm{~g} \mathrm{~cm}^{-3}$. The regenerated filter carbon (RWF-C) has the largest volume $\left(8.00 \mathrm{~g} \mathrm{~cm}^{-3}\right)$. Probably, trace chemicals during the regenerating process caused the anomaly.

\section{Ammonia Adsorption Test of the Activated Carbon}

The mean optimum contact time between 4 sheets of ACC (containing a total of $1.4 \mathrm{~g}$ stuck carbon particles) and the initial concentration of ammonia vapor $(0.0052 \mathrm{M})$ was $100 \mathrm{~min}$ at $1 \mathrm{~atm}$ and $28 \pm 1{ }^{\circ} \mathrm{C}$. The adsorption capacity of ACC with a different type of carbon source is tabulated in Table 2. WF-C and RWF-C have an adsorption capacity of $7.038 \pm 0.2$ and $6.246 \pm$ $0.07 \mathrm{mg}$ ammonia per gram of carbon. The WF-C and RWF-C were made of coconut shells and as commercialized water filter products.

Table 2. Experimental adsorption of ACC toward ammonia vapor at $28^{\circ} \mathrm{C}$ and $1 \mathrm{~atm}$

\begin{tabular}{|c|c|c|c|c|}
\hline Type of Carbons & $\begin{array}{l}\text { Total weight } \\
\text { stuck C (g) }\end{array}$ & $\begin{array}{c}\text { Total of } \\
\text { ACC sheets }\end{array}$ & $\begin{array}{l}\text { Area } \\
\left(\mathrm{cm}^{2}\right)\end{array}$ & $\begin{array}{c}\text { Adsorption capacity } \\
\text { (total mg ammonia. } \mathrm{g}^{-1} \text { carbon) }\end{array}$ \\
\hline \multirow{6}{*}{$\begin{array}{l}\text { WF-C } \\
\text { (coconut shell carbon) }\end{array}$} & 0.294 & 1 & 22.75 & 6.681 \\
\hline & 0.616 & 2 & 45.5 & 7.123 \\
\hline & 1.048 & 3 & 68.25 & 7.208 \\
\hline & 1.419 & 4 & 91 & 7.140 \\
\hline & 1.869 & 5 & 113.8 & 7.038 \\
\hline & & & & $7.038 \pm 0.2$ \\
\hline \multirow{6}{*}{$\begin{array}{l}\text { RWF-C } \\
\text { (coconut shell carbon) }\end{array}$} & 0.302 & 1 & 22.75 & 6.137 \\
\hline & 0.613 & 2 & 45.5 & 6.273 \\
\hline & 1.009 & 3 & 68.25 & 6.290 \\
\hline & 1.323 & 4 & 91 & 6.307 \\
\hline & 1.658 & 5 & 113.8 & 6.222 \\
\hline & & & & $6.246 \pm 0.07$ \\
\hline \multirow{6}{*}{$\begin{array}{l}\text { Palm-act-prior-carb-C } \\
\text { (palm kernel shell carbon) }\end{array}$} & 0.399 & 1 & 22.75 & 2.771 \\
\hline & 0.701 & 2 & 45.5 & 2.873 \\
\hline & 1.125 & 3 & 68.25 & 2.873 \\
\hline & 1.409 & 4 & 91 & 2.873 \\
\hline & 1.76 & 5 & 113.8 & 2.873 \\
\hline & & & & $2.853 \pm 0.05$ \\
\hline \multirow{6}{*}{$\begin{array}{l}\text { Palm-carb-prior-act-C } \\
\text { (palm kernel shell carbon) }\end{array}$} & 0.35 & 1 & 22.75 & 1.275 \\
\hline & 0.697 & 2 & 45.5 & 1.428 \\
\hline & 1.146 & 3 & 68.25 & 1.445 \\
\hline & 1.456 & 4 & 91 & 1.445 \\
\hline & 1.843 & 5 & 113.8 & 1.428 \\
\hline & & & & $1.404 \pm 0.07$ \\
\hline
\end{tabular}



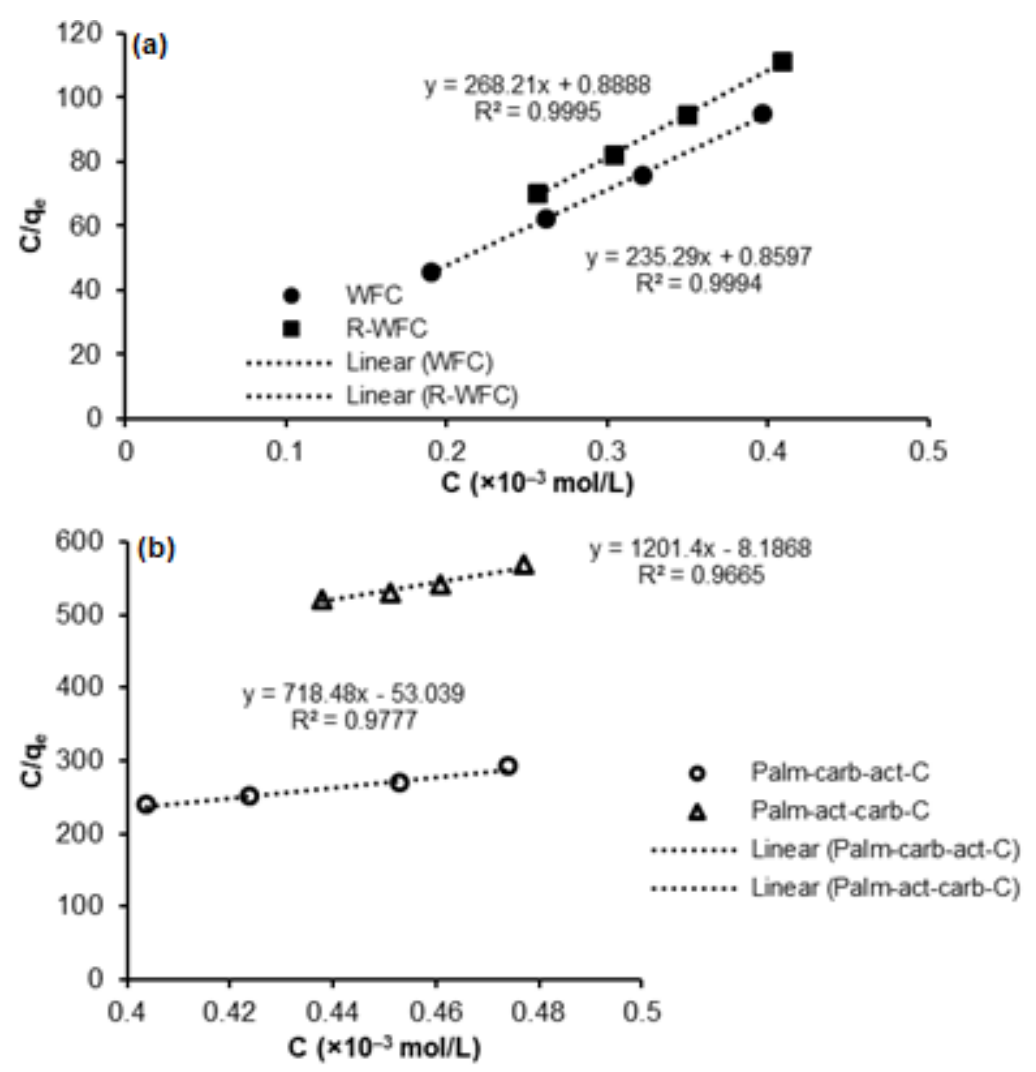

Fig 6. Isothermal Langmuir plot of ammonia vapor adsorption on several types of activated carbon cloth made of (a) commercial water filter carbon and the regenerated one, (b) palm kernel activated carbon prepared with different activation sequences

The adsorption capacity of these sources of carbon is higher than palm kernel carbons.

Since the adsorption occurs between the gas (ammonia vapor) and solid adsorbent (ACC), the Langmuir model was chosen to study the adsorption model verifying literature [20]. We plot $\left(\mathrm{C} / \mathrm{q}_{\mathrm{e}}\right)$ vs. $\mathrm{C}$ and found linear graphs with $\mathrm{R}^{2}$ of 0.9995 and 0.9994 . The Freundlich plot gave a smaller $\mathrm{R}^{2}$ that is the highest with only 0.8667 , and other models have not been studied [29]. The ammonia adsorption characteristics of several activated carbons were presented as a plot graph in Fig. 6 . They were all found to be linear following the isothermal Langmuir law. Refer to equation (2), the graph plotted in Fig. 6 shows that the $b$ value can be calculated as the reversed gradient and multiply by 1000 as the concentration correction factor. The $b$ for $y=235.29 x+0.86$ (WFC), $y=268.21 x+$ 0.88 (R-WFC); $y=1201.1 \mathrm{x}-8.1868$ (Palm-act-carb) and $718.48 \mathrm{x}-53.04$ (Palm-carb-act) are 4.25, 3.37, 1.39, and $0.83 \mathrm{mg} \mathrm{g}^{-1}$ respectively at operating temperature of $28^{\circ} \mathrm{C}$.
These calculated data are much smaller than the experimental adsorption capacities (Table 2) but higher than the adsorption capacity prepared active carbon previously reported, which was $0.6-1.7 \mathrm{mg} \mathrm{g}^{-1}$ at $40{ }^{\circ} \mathrm{C}$ [30]. The difference in adsorption capacity between experimental and graph data analysis might relate to fewer data plotted and the graph correction factor. The trend was consistent between the SEM and BET data, which showed palm shell activated carbon has comparable adsorption capacity to the commercial water filter carbon made from coconut shell-activated charcoal. The slightly higher adsorption capacity of WF$\mathrm{C}$ is in line with the findings of previous reports that coconut carbon has a higher adsorption capacity than those produced by Palm Kernel Shell (PKS) [31-32]. Still, in the Asian community, PKS has much larger resources and waste than coconut shells.

Adsorption capacity enhancement of Palm-actprior carb-C might relate to a chemical reaction between 
$\mathrm{NaOH}$ and PKS cellulose prior to the carbonization process. By soaking palm kernel shells in $\mathrm{NaOH}$ before the carbonization process, it causes cellulose to swell and fragment. This effect subsequently made more porous carbon after the carbonation process [33]. The phenomenon no longer worked for the activated carbon prepared in the reverse process (in the case of Palm-carbprior act-C). The carbon particles were already inert toward $\mathrm{NaOH}$, and thereby the adsorption capacity was lower. Since PKS was activated by $\mathrm{NaOH}$ and the trace has been washed until neutral, then ACC active sites for adsorption were plausibly just the carbon porosity. Analog to the previous study that, unlike the $\mathrm{KOH}$ activation, the $\mathrm{NaOH}$-activated biochar showed no obvious FTIR spectra between 4000-400 $\mathrm{cm}^{-1}$. It indicated that chemical functional groups on the biochar surface were relatively absent [34]. Refer to this previous report, adsorption in this current study is predicted due to the physical interaction between ammonia and carbon pores in the surface of ACC. The molecular interaction type also confirmed the Langmuir isothermal model (Fig. 6) [35]. This finding verified the previous report that suggested both Langmuir isothermal model and physisorption for the adsorption of ammonia gas onto activated carbon [30]. The experiment was comparable to our work in that it was carried out in the gas phase and at relatively low temperatures. Adsorption studies of carbon-ammonia in aqueous solution were previously reported to follow the Freundlich instead of the Langmuir adsorption model [36]. The BET graph plots (Fig. 5) also showed desorption models representing the physical interaction characteristics.

\section{Skim Latex Odor Removal}

The skim latex released some volatile organic compounds (VOCs) with unpleasant odors, especially from the low molecular weight of carboxylic acid components; they are natural compounds and relatively none of the recognized toxic chemicals [37]. The PKS ACC was applied to absorb skim latex odor, which is VOCs. The PKS ACC performance was attempted to compare to WF-ACC. The odor-reducing performance was analyzed based on the panelist's responses during the organoleptic test. From 20 panelists, 100\% of respondents agreed that the control sample (skim latex vapor without ACC adsorbent) has the worse smell with a level of 10 . They also confirmed that the empty container was odorless with a level of 0 . After treating skim latex odor with $45.5 \mathrm{~cm}^{2}$ of ACC (2 pieces with @ $3.5 \times 6.5 \mathrm{~cm}^{2}$ ) at optimum contact time in a close container, the majority (55\%) respondents smell that odor had been in medium with the level of 5-7, but the rest respondents still feel that the scent remains worse. However, after treating the skim latex vapor with $113.75 \mathrm{~cm}^{2}$ of ACC (5 pieces), nearly all respondents agreed that the odor had been at a deficient level. About $60 \%$ of respondents scored the odor level being reduced to level 2; the rest marked it as level 1 . The respondents could not differentiate the effect of different source carbon on the ACCs odor reduction capacity.

\section{- CONCLUSION}

The activation-carbonization sequence of palm kernel shells using $\mathrm{NaOH}$ as the activator significantly affects activated carbon quality. The treatment prepared by initially activating palm kernel before carbonization gave better properties than those prepared with the reciprocal sequence. The activated carbon prepared with a new model pyrolysis chamber fulfilled the Indonesian industrial standard, and the quality is comparable with commercial-water- filter-activated carbons. The regenerated WF-C shows high adsorption capacity. The carbon particle stability on the ACC surface was affected by both the adhesive concentration and size. The adsorption capacity of ACC made of palm kernel shell toward ammonia vapor is lower than that of commercial water filter carbon made, which is made of coconut shell carbon, but kernel ACC has the comparable capacity with other work previously published. The ACC also showed a high capacity to reduce the skim-latex-odor level depending on its ACC area and odor quantity.

\section{- ACKNOWLEDGMENTS}

We highly appreciated research funding provided by Universitas Syiah Kuala, Aceh Province Indonesia, in 2019 financial years with Research Grant number: 
520/UN11/SPK/PNBP/2019 (February 8, 2019); also the second grant; 268/UN11/SPK/PNBP/2020 (March 17, 2020).

\section{- AUTHOR CONTRIBUTIONS}

M. Adlim is the corresponding author who composed the main manuscript. Ratu F.I. Rahmayani, Fitri Zarlaida, and Latifah Hanum monitored research activities in the laboratory. Maily Rizki, Nurul U. Manatillah, and O. Muktaridha were undergraduate and graduate students who conducted the experiments in the laboratory.

\section{- REFERENCES}

[1] Guthrie, S., Giles, S., Dunkerley, F., Tabaqchali H., Harsfield, A., Loppolo, B., and Manville, C., 2018, The impact of ammonia emissions from agriculture on biodiversity, RAND Corporation, Cambridge, UK.

[2] National Research Council (US) Committee on Acute Exposure Guideline Levels, 2008, Acute Exposure Guideline Levels for Selected Airborne Chemicals: Volume 6, National Academies Press, Washington, DC.

[3] Mokhtar, N.M., Lau, W.J., Ismail, A.F., and Veerasamy, D., 2015, Membrane distillation technology for treatment of wastewater from rubber industry in Malaysia, Procedia CIRP, 26, 792-796.

[4] Dejchanchaiwong, R., Kumar, A., and Tekasakul, P., 2019, Performance and economic analysis of natural convection based rubber smoking room for rubber cooperatives in Thailand, Renewable Energy, 132, 233-242.

[5] Dejchanchaiwong, R., Tirawanichakul, Y., Tirawanichakul, S., Kumar, A., and Tekasakul, P., 2017, Techno-economic assessment of forcedconvection rubber smoking room for rubber cooperatives, Energy, 137, 152-159.

[6] Anisuzzaman, S.M., Bono, A., Krishnaiah, D., and Tan, Y.Z., 2016, A study on dynamic simulation of phenol adsorption in activated carbon packed bed column, J. King Saud Univ. Eng. Sci., 28 (1), 47-55.

[7] Bertone, E., Chang, C., Thiel, P., and O'Halloran, K., 2018, Analysis and modelling of powdered activated carbon dosing for taste and odour removal, Water Res., 139, 321-328.

[8] Otulana, J.O., Oluwole, O.O., and Adeleke, M.B., 2016, A reactor plant for activated carbon production, Int. J. Novel Res. Eng. Sci., 2 (2), 20-26.

[9] Menya, E., Olupot, P.W., Storz, H., Lubwama, M., and Kiros, Y., 2018, Production and performance of activated carbon from rice husks for removal of natural organic matter from water: A review, Chem. Eng. Res. Des., 129, 271-296.

[10] Mohammad Razi, M.A., Al-Gheethi, A., Al-Qaini, M., and Yousef, A., 2018, Efficiency of activated carbon from palm kernel shell for treatment of greywater, Arab J. Basic Appl. Sci., 25 (3), 103-110.

[11] Cukierman, A.L., 2013, Development and environmental applications of activated carbon cloths, Int. Scholarly Res. Not., 2013, 261523.

[12] Attia, N.F., Jung, M., Park, J., Jang, H., Lee, K., and Oh, H., 2020, Flexible nanoporous activated carbon cloth for achieving high $\mathrm{H}_{2}, \mathrm{CH}_{4}$, and $\mathrm{CO}_{2}$ storage capacities and selective $\mathrm{CO}_{2} / \mathrm{CH}_{4}$ separation, Chem. Eng. J., 379, 122367.

[13] Tripathi, N.K., Singh, V.V., Sathe, M., Thakare, V.B., and Singh, B., 2018, Activated carbon fabric: An adsorbent material for chemical protective clothing, Def. Sci. J., 68 (1), 83-90.

[14] Eza, T.S.M., Wan Ahmad, W.Y., Omar, K., and Ahmad, M.N., 2014, Effectiveness of activated carbon produced from coconut and palm shells as anti-odour on textile fabrics, Indian J. Fibre Text. Res., 39, 190-195.

[15] Ayinla, R.T., Dennis, J.O., Zaid, H.M., Sanusi, Y.K., Usman, F., and Adebayo, L.L., 2019, A review of technical advances of recent palm bio-waste conversion to activated carbon for energy storage, $J$. Cleaner Prod., 229, 1427-1442.

[16] Lelifajri, Nawi, M.A., Sabar, S., Supriatno, and Nawawi, W.I., 2018, Preparation of immobilized activated carbon-polyvinyl alcohol composite for the adsorptive removal of 2, 4dichlorophenoxyacetic acid, J. Water Process Eng., $25,269-277$. 
[17] Da'na, E., and Awad, A., 2017, Regeneration of spent activated carbon obtained from home filtration system and applying it for heavy metals adsorption, J. Environ. Chem. Eng., 5 (4), 3091-3099.

[18] Guo, H., Weber, R.J., and Nenes, A., 2017, High levels of ammonia do not raise fine particle $\mathrm{pH}$ sufficiently to yield nitrogen oxide-dominated sulfate production, Sci. Rep., 7 (1), 12109.

[19] Smeets, M.A.M., Bulsing, P.J., van Rooden, S., Steinmann, R., de Ru, J.A., Ogink, N.W.M., van Thriel, C., and Dalton, P.H., 2007, Odor and irritation thresholds for ammonia: A comparison between static and dynamic olfactometry, Chem. Senses, 32 (1), 11-20.

[20] Ayawei, N., Ebelegi, A.N., and Wankasi, D., 2017, Modelling and interpretation of adsorption isotherms, J. Chem., 2017, 3039817.

[21] Kul, A.R., and Caliskan, N., 2009, Equilibrium and kinetic studies of the adsorption of $\mathrm{Zn}$ (II) ions onto natural and activated kaolinites, Adsorpt. Sci. Technol., 27 (1), 85-105.

[22] Juntarachat, N., Bouvier, N., Lepoutre, J.P., Roland, A., Sainte-Beuve. J., Granet, F., Salmon, J.M., Rigou, P., and Chalier, P., 2013, Identification by GC-O and GC-MS of new odorous compounds in natural rubber, J. Appl. Polym. Sci., 130 (3), 1863-1872.

[23] Dada, A.O., Inyinbor, A.A., and Oluyori, A.P., 2012, Preparation and characterization of activated carbon using coconut and palm kernel shells, Sci. Focus, 17 (2), 188-197.

[24] Arami-Niya, A., Wan Daud, W.M.A., Mjalli, F.S., Abnisa, F., and Shafeeyan, M.S., 2012, Production of microporous palm shell-based activated carbon for methane adsorption: Modeling and optimization using response surface methodology, Chem. Eng. Res. Des., 90 (6), 776-784.

[25] Sumathi, S., Bhatia, S., Lee, K.T., and Mohamed, A.R., 2009, Optimization of microporous palm shell activated carbon production for flue gas desulphurization: Experimental and statistical studies, Bioresour. Technol., 100 (4), 614-1621.

[26] Rashidi, N.A., and Yusup, S., 2017, A review on recent technological advancement in the activated carbon production from oil palm wastes, Chem. Eng. J., 314, 277-290.

[27] Wilcox, J., 2012, “Adsorption” in Carbon Capture, Springer, New York, 115-176.

[28] Thommes, M., Kaneko, K., Neimark, A.V., Olivier, J.P., Rodriguez-Reinoso, F., Rouquerol, J., and Sing, K.S.W., 2015, Physisorption of gases, with special reference to the evaluation of surface area and pore size distribution (IUPAC Technical Report), Pure Appl. Chem., 87 (9-10), 1051-1069.

[29] Nandiyanto, A.B.N., Girsang, G.C.S., Maryanti, R., Ragadhita, R., Anggraeni, S., Fauzi, F.M., Sakinah, P., Astuti, A.P., Usdiyana, D., Fiandini, M., Dewi, M.W., and Al-Obaidi, A.S.M., 2020, Isotherm adsorption characteristics of carbon microparticles prepared from pineapple peel waste, Commun. Sci. Technol., 5 (1), 31-39.

[30] Rodrigues, C.C., de Moraes, D., da Nóbrega, S.W., and Barboza, M.G., 2007, Ammonia adsorption in a fixed bed of activated carbon, Bioresour. Technol., 98 (4), 886-891.

[31] Hidayu, A.R., and Muda, N., 2016, Preparation and characterization of impregnated activated carbon from palm kernel shell and coconut shell for $\mathrm{CO}_{2}$ capture, Procedia Eng., 148, 106-113.

[32] Ademiluyi, F.T., and David-West, E.O., 2012, Effect of chemical activation on the adsorption of heavy metals using activated carbons from waste materials, Int. Scholarly Res. Not., 2012, 674209.

[33] Zhang, S., Wang, W.C., Li, F.X., and Yu, J.Y., 2013, Swelling and dissolution of cellulose in $\mathrm{NaOH}$ aqueous solvent systems, Cellul. Chem. Technol., 47 (9-10), 671-679.

[34] Hsu, D., Lu, C., Pang, T., Wang, Y., and Wang, G., 2019, Adsorption of ammonium nitrogen from aqueous solution on chemically activated biochar prepared from sorghum distillers grain, Appl. Sci., 9 (23), 5249.

[35] Kecili, R., and Hussain, C.M., 2018, "Mechanism of adsorption on nanomaterials" in Nanomaterials in Chromatography, Eds. Hussain, C.M., Elsevier, Amsterdam, 89-115. 
[36] Long, X.L., Cheng, H., Xin, Z.L., Xiao, W.D., Li, W., and Yuan, W.K., 2008, Adsorption of ammonia on activated carbon from aqueous solutions, Environ. Prog., 27 (2), 225-233.
[37] Kamarulzaman, N.H., Le-Minh, N., and Stuetz, R.M., 2019, Identification of VOCs from natural rubber by different headspace techniques coupled using GC-MS, Talanta, 191, 535-544. 